\title{
EL VICIO DE CRITICAR: TEORÍA, CRÍTICA Y POLÉMICA SEGÚN ALBERTO CARDÍN
}

The critic's vice: theory, criticism and polemics according to Alberto Cardín

\author{
RODRIGO LÓPEZ MARTÍNEZ \\ UNIVERSITY OF MANCHESTER (REINO UNIDO) \\ UNIVERSIDAD DE BUENOS AIRES (ARGENTINA) \\ rodrigo_lopez@hotmail.es https://orcid.org/0000-0002-0049-3832
}

RECIBIDO: 05 DE JULIO DE 2020

ACEPTADO: 21 DE OCTUBRE DE 2020

RESUMEN: De cara a una transición democrática caracterizada por la dual e interdependiente normalización de los campos político y cultural, Alberto Cardín emerge como una figura incómoda, marginal y a día de hoy relativamente olvidada. Revisitar sus intervenciones polémicas en publicaciones como Revista de Literatura y Diwan habilita una aproximación integral a sus apuestas intelectuales, capaz de hallar discusiones aún actuales y productivas al momento de leer la transición a contrapelo. Pionero introductor del psicoanálisis lacaniano en España, el diálogo entablado entre Cardín y el argentino Oscar Masotta delinea una perspectiva distintivamente teórica con que interrogar qué sujeto intelectual adviene al renovado escenario posfranquista. Mientras denuncia el reacomodamiento que la transición supone para los más célebres intelectuales españoles, Cardín lleva adelante una apuesta crítica alternativa en su misma inmanencia textual. Apela a la diatriba y a la polémica no solo como instrumentos de disputa en el campo cultural, sino que las adopta de modo que terminen por devenir forma: hace de ellas procedimientos con los que redefinir y reivindicar la especificidad discursiva de una crítica que se asume como tal solo mediante la asunción radical del conflicto y la diferencia, irreductibles a todo llamamiento consensual.

PALABRAS CLAVE: Cardín, Masotta, psicoanálisis, teoría, transición.

ABSTRACT: In face of a democratic transition characterized by the mutually dependent normalization of the cultural and political fields, Alberto Cardín emerges as an uncomfortable, marginal and relatively forgotten personality. Revisiting his polemical interventions in magazines like Revista de Literatura and Diwan allows us to integrally address his intellectual stakes, as well as to find still productive discussions with which to brush the transition against the grain. As a pioneer introducer of Lacanian psychoanalysis in Spain, the dialogue between Cardín and the Argentinean Oscar Masotta delineates a distinctively theoretical perspective in regards to the redefinition of the intellectual subject in the renewed post-Franco scene. While denouncing the transition's rearrangement of the most celebrated Spanish intellectuals, Cardín puts forward an alternative critical stake in its own textual immanency. He invokes diatribes and polemics not only as confrontational tools in the cultural field, but he adopts them as properly formal means: with them, Cardín redefines and vindicates the discursive specificity of criticism as the radical assumption of irreducible conflicts and differences, opposed to any summon to consensus.

KEYWORDS: Cardín, Masotta, psychoanalysis, theory, transition. 


\section{¿QUIÉN TEME A ALBERTO CARDÍN?}

Director de la primera colección editorial de temática homosexual en España, pionero activista en materia de SIDA, traductor contemporáneo de Copi, impulsor de la renovación posestructuralista de la teoría literaria vernácula. Credenciales suficientes para hacer de cualquiera un objeto de culto en el panteón académico. Empero, un prontuario paralelo y contradictorio podría explicar el relativo olvido al que el medio cultural hispano ha condenado a Alberto Cardín: temprano ladero del hoy ultraliberal Federico Jiménez Losantos, firmante del anticatalanista Manifiesto de los 2300, abierto detractor de las políticas del Front d'Alliberament Gai de Catalunya, votante del sí en el referéndum sobre la permanencia de España en la OTAN de 1986.

Inasimilable por derecha o izquierda, Cardín se revela como una figura intelectual excesiva, incómoda o insoportable en el panorama de la transición española. Incomodidad reflejada en el sesgo parcial con que pasadas iniciativas académicas, usualmente con acento anglosajón, han reivindicado su personalidad. Smith afirma que Cardín corporiza un rol sin precedentes en el contexto español, aquel del "intelectual homosexual", anómalo en el habitus de la vida cultural posfranquista (2000: 137). Vilaseca replantea este dictamen de anomalía a través de un prisma conceptual queer, según el cual Cardín "embraced the burden of negativity with which homosexuality was invested in the Spain of his time" (2010: 181). En el ámbito hispano, Aliaga y Cortés reconocen el pionero aporte de Cardín a la difusión de la problemática del SIDA (1993), mientras que Mira critica un "individualismo feroz, casi desmesurado" (1999: 155) en la resistencia de Cardín ante toda articulación identitaria e institucionalización asimilacionista, traducible en "imposibilidad de articular el discurso en términos políticos" y "distanciamiento respecto de sus aliados (presuntamente) naturales" (2004: 469-473). Señala Mira que Cardín ocupa una posición excéntrica respecto del activismo homosexual: "la desconfianza fue mutua. A pesar de sus vínculos personales con las figuras más relevantes, su actitud pública siempre fue de sarcasmo e irrisión, y el movimiento respondió con ninguneo" (2004: 470).

Igualmente excéntrico emerge Cardín en el ambiente underground catalán, así recordado por el mismísimo Nazario: “Ocaña incluía a Cardín en un menospreciado grupo al que llamaba despectivamente 'intelectualas', pero lo usaba para que sus chulos le sacaran la pasta. Los novios de Ocaña [...] cobraban una buena tarifa a Cardín" (2016: 58). Epítetos como "anómalo", "excéntrico" e "intelectuala" cifran el carácter insoportable de Cardín cuando de rever la transición se trata, así como el relativo silencio que rodea su figura en los habituales recuentos del período. El propio Jiménez Losantos provee una oportuna síntesis de la incomodidad suscitada por Cardín, al evocar el primer encuentro con quien posteriormente sería su aliado intelectual:

Alberto Cardín se presentó de golpe una noche en las reuniones del Instituto Alemán, recién llegado de Canadá. Lucía un abrigo de piel rojo brillante, un maquillaje dorado y un pendiente, cosa entonces rarísima. [...] Lo que resultaba insólito era contemplar a un personaje con esa apariencia sosteniendo un severo discurso marxista y revolucionario, amén de anticonvencional, antifamiliar y antiloquefuera. (1995: 29)

Es precisamente esta actitud "antiloquefuera" el complemento a la reivindicación parcial de Cardín en tanto "intelectual homosexual", para así dar lugar a una aproximación integral a sus apuestas intelectuales. Hacer de lo insoportable un posicionamiento teórico-crítico radical e 
intransigente tout court habilita un punto de vista desde donde revisitar las intervenciones polémicas de Cardín, sus enfrentamientos con instituciones y actores del medio cultural de la transición, sus denuncias respecto del consenso por entonces en vías de afianzamiento, por ejemplo, desde las páginas de uno de sus grandes némesis, el diario El País. Bajo esta óptica, cobra renovado relieve la iniciativa de los editores catalanes de Ultramarinos, quienes en 2016 compilan la poesía completa de Cardín bajo el título de Mi más hermoso texto. No resulta casual el paralelo entre las reseñas que El País dedica a la edición original de su poemario Despojos y a la antología de Ultramarinos. Si en 1982 afirmaba "Segundo libro de poemas de este conocido polemista, caracterizado por un tono de pesimismo, ironía y nihilismo", en 2016 condena la decisión editorial de incorporar textos polémicos como apéndice de la antología poética: "No sé si era el lugar para estas cosas. Los poemas se dirigen a la memoria. Los documentos, al olvido" (2016). Coherente condena al olvido, mismo desdén a una misma provocación, tras 34 años, por parte del periódico abiertamente defenestrado por Cardín en aquellas intervenciones polémicas.

Si Cardín brilla por insoportable e incordioso sin cuartel, su vocación marginal resulta indisociable de la propia escritura y forma textual donde aspiró a ejercerla. Desde las páginas de Revista de Literatura (1974-77) y Diwan (1978-82), Cardín lanza una vehemente interrogación a un escenario político y cultural en proceso de realineación e institucionalización tras la muerte de Franco. Cardín apela a la diatriba y a la polémica no solo como instrumentos de disputa en el campo cultural, sino que las adopta de modo que terminen por devenir forma: hace de ellas procedimientos con los que redefinir y reivindicar la especificidad discursiva de la crítica. La apuesta textual de Cardín por la crítica resulta causa y efecto a la vez de su marginalidad, cifra de una postura intelectual que combate el malestar en la cultura desde la impugnación radical, malestar corporizado en las líneas hegemónicas de la transición.

Distintos hitos históricos jalonan las usuales periodizaciones de la transición. El asesinato de Carrero Blanco en 1973 opera como usual momento inaugural, mientras que la fecha de clausura varía entre la redacción de la Constitución (1978), el golpe de Estado de Antonio Tejero (1981), la victoria del PSOE (1982) o los Juegos Olímpicos de Barcelona (1992). Cualquiera sea la periodización, la trayectoria biográfica de Cardín atraviesa de lleno la transición, desde su llegada a Barcelona en 1973, tras cursar estudios de Historia y Antropología y realizar trabajo de campo en Canadá, pasando por su época de más intensa discusión político-cultural durante los años de Revista de Literatura y Diwan, para hacia mediados de los ochenta dedicarse a la enseñanza en la Universidad de Barcelona hasta su muerte en 1992. Queda así trazado un arco de continuidad entre las polémicas entabladas por Cardín y los interrogantes con que este período resulta cuestionado desde la actualidad. Desde su colocación y vocación marginal en el contexto de la transición, se vislumbra el trazado de las fuerzas en tensión en un momento de particular intensidad. Las intervenciones críticas de Cardín no solo habilitan nuevas perspectivas sobre los silencios de la "historia oficial", sino que además permiten interpelar las condiciones políticas y culturales de nuestro presente: ¿qué nos habla aún hoy desde los debates coyunturales de Cardín? ¿Cómo responden nuestras problemáticas y urgencias intelectuales a sus demandas polémicas? 


\section{EL SÍNTOMA TRANSICIÓN}

Cardín recurre en 1978 al arsenal teórico del psicoanálisis lacaniano para caracterizar a la España posfranquista como "la nación más freudiana de la tierra" (1978: 131). Demuele el hoy denostado consenso, que para él connota la renegación del inconsciente de un país que, pretendiéndose el "más dialogante del universo mundo, practica la incomunicación como ninguno" (1978: 31). Posterior y paralelamente, para Vilarós la transición se erige sobre un "pacto de olvido", el cual freudianamente reprime los traumas de la guerra civil y garantiza un pasaje aproblemático desde la dictadura a la democracia; traza así un eje de continuidad entre la bonanza económica del desarrollismo franquista y el consenso político ulterior: "la voluntad social que exige una restauración democrática pasa sobre todo por la querencia de integración de la sociedad española en el aparato económico global impulsado por el capitalismo tardío" (2018: 1881).

Institucionalización "por arriba" de mecanismos de política representativa y, "por abajo", de formas ciudadanía, proceso de integración de España en el mapa capitalista global, "el precio de la transición" lo conforma la invisibilización de vías alternativas, futuros pasados de praxis política y vital, así como de nombres propios y formas discursivas inasimilables a los estándares consensuales (Labrador, 2014: 361; Morán, 2015: 495). Metonímico y especular correlato de "los límites de la libertad" democrática, la consolidación del campo cultural posfranquista normaliza una renovada escena intelectual reglada por la cooptación y dependencia institucional, sea del estado o de la industria mediática, de cuanta iniciativa cultural sirva a un despolitizado sentido común socialdemócrata ${ }^{2}$. La desactivación de la cultura crítica en España respondería a un proyecto estatal irrealizable sin una alianza mutuamente beneficiosa con los intereses económicos de los medios de comunicación, capaces de estipular la circulación de discursos culturales en un mercado de consumidores. Queda perfilado el impacto modélico de una stasis socio-política que, una vez estabilizado el régimen democrático y tras la victoria del PSOE en 1982, cristaliza en el paradigma que Martínez (2012) denomina CT o Cultura de la Transición.

En el prólogo a su ensayo Como si nada (1981), Cardín hace de su propia colocación marginal una clave interpretativa del campo cultural transicional, al que denomina "villorrio global". Homologa las fronteras discursivas del consenso a las estructuras de la industria cultural donde este se expresa, ambas interdependientes y afianzadas en línea de continuidad entre tardofranquismo y transición (1981: IV). Lanza sus vituperios hacia figuras intelectuales a las que denomina "pregoneros", como Fernando Savater, José Luis López Aranguren o Juan Goytisolo, quienes con el pasaje entre regímenes pasarían a ocupar la primera plana de los medios masivos, para tan solo replicar en clave cultural el señuelo del diálogo político esbozado por los líderes partidarios: "cuando se elimina la diatriba en aras de una concordia que pertenece a la convivencia política, pero no al campo de la cultura, son individuos tan torpes como los políticos los que acaban tomando en rehenes la palabra” (1981: XIX). Para Cardín, tal engañosa concordia entre pregoneros se produce a pesar de sus alineamientos ideológicos explícitos, que podrían ser

\footnotetext{
1 Labrador Méndez, Germán. “¿Lo llamaban democracia? La crítica estética de la política en la transición española y el imaginario de la historia en el 15-M". Kamchatka. Revista de análisis cultural 4 (2014): 11-61.

2 Quaggio destaca el rol de políticas culturales estatales en la reconfiguración de la identidad democrática española, a partir de iniciativas del Ministerio de Cultura instituido en 1977: "actuó como una especie de amalgama institucional de las nuevas veleidades modernizadoras, en clave cultural, de la España monárquica y democrática” (2014: 1781).
} 
incluso antagónicos, cada vez que estos obvian interrogar las condiciones de producción con que la industria cultural ampara su masiva visibilidad: "no son las alineaciones derecha/izquierda, ni siquiera liberales/dogmáticos las que verdaderamente importan [...] [sino] los puntos más molestos, aquellos que hacen a la inserción de los sujetos en su propia cultura" (1981: LXV).

La descalificación de "pregoneros" lanzada por Cardín anticipa tipificaciones como "intelectuales bonitos" (de Miguel, 1980), "mandarines de la cultura" (Morán, 2014) o "desfachatados" (Sánchez Cuenca, 2016), las que refieren al realineamiento de la figura del intelectual en la transición, movimiento indisociable de la integración a dinámicas capitalistas globales y de la mercantilización/espectacularización de la producción cultural (Fernández, 2014: $219)^{3}$. Emerge en este escenario el "intelectual mediático", cuya participación se orienta hacia los géneros y tribunas de opinión de la prensa diaria, dando lugar a una "sobrevaloración de su imagen pública" y a "un prestigio que no está directamente ligado a su obra como intelectuales" (Morán, 2015: 3565; Pecourt, 2016: 120). El afianzamiento de un campo cultural estrechamente ligado al mercado motiva reubicaciones y compromisos, a riesgo de "caerse del mapa", al marco y reglas de juego de los medios masivos de comunicación (Labrador, 2017: 6830).

Cardín apela a su propio desalojo de las páginas de El País, donde publica un puñado de reseñas antes de colisionar con sus criterios de redacción, para arremeter contra el periódico en tanto "órgano de expresión del villorrio global" y "boletín oficial de la cultura". Para Cardín, El País se erige como adalid de la democracia mediante la confusión de los planos político y cultural:

Mientras el funcionamiento político de nuestra sociedad civil iba adquiriendo su normalización por la vía del aprendizaje de unas formas de comportamiento cívico, a cuya difusión El País ha contribuido de manera inequívoca, la cultura iba sufriendo en las páginas de dicho periódico un proceso de supuesta normalización consistente en aplicarle el mismo rasero de la desdramatización y la concordia. (1981: XXV)

La normalización del campo cultural equivaldría a la "muerte de la cultura por falta de discusión”, con lo que Cardín convierte su propia proscripción de El País en índice revelador de los límites que una "política de estado de la cultura" aplicaría a la libertad de expresión (1981: XXVII). Recuenta el destino de "papelera" que el "chico para todo" de la sección cultural de El País da a sus últimas reseñas, para allí denunciar la censura implícita con que las redacciones de los periódicos trabarían contornos de "fidelitas" entre nombres siempre repetidos, dando lugar a una "férrea red de criba de las ideas" (1981: XXXI). Cardín impugna como "sarcófago del reseñismo" al suplemento Arte y pensamiento, previo a Babelia, el cual materializaría en clave cultural el repertorio de inclusiones y exclusiones que el marco institucional del consenso impone a la política de "lo posible": "aparecer en sus páginas no es solo promesa de venta segura, sino, sobre todo, garantía de existencia, certificación ontológica” (1981: XXIII).

Al izar como posición enunciativa aquella del intelectual no-establecido, del "inexistente" en la escena cultural, Cardín denuncia la condición de "referencia dominante" con que Imbert y Vidal Beneyto (1986) caracterizan el "poder performativo" y de "mediador social" de El País. El

\footnotetext{
3 Fernández, Álvaro. "La mirada histórica. Estrategias para abordar la cultura de la transición española”. Kamchatka. Revista de análisis cultural 4 (2014): 209-232.
} 
País emerge, entre otros epítetos, como "representante formal de una opinión pública que ha contribuido él mismo a formar", "guardián del espíritu democrático" o "microrretrato de la transición" (Gracia, 2019). En tanto "aglutinante intelectual”, encuadre de una pluralidad de firmas tan dispares como el liberal Pedro Laín Entralgo, el cristiano de izquierda Aranguren y el anarco-nihilista Savater, El País condensa "la cultura estándar de la transición" (Pecourt, 2008: 247) y actúa "como formalizador de un campo ideológico y cultural, como delimitador de un espacio finito de discursos posibles" (Plata Parga, 2010: 199). La conjunción de política, cultura y mercado conlleva no solo que el canon cultural del paradigma CT se cifre en el repertorio de nombres valorado y promovido desde El País (Labrador, 2017: 1382), sino también que lo haga desde un marco y forma discursiva determinada: el suplemento cultural y la reseña (León, 2012: 1381). Los embates de Cardín contra El País son entonces eco de un fenómeno socio-cultural extensible a la España resultante de la transición: el retroceso del radicalismo ideológico en el horizonte político se replica, en el campo cultural, con el eclipse de las revistas político-culturales y la consiguiente valorización e influencia de la prensa de masas (Morán, 2014: 9976).

$\mathrm{Si}$, por un lado, las invectivas lanzadas por Cardín hacia el villorrio global y los pregoneros subrayan el rediseño de un campo cultural institucionalizado y los reacomodos a su amparo, por otro lo hacen mediante la disputa del propio género textual donde los intelectuales mediáticos consolidan su prestigio. En este sentido, revisitar las intervenciones polémicas de Cardín conlleva no solo la confirmación retrospectiva de imposturas intelectuales sabidas de antemano, sino además la reevaluación de una apuesta crítica alternativa en su misma inmanencia textual.

\section{¿TELQUELISMO HISPANO?}

El umbral transicional testimonia el apogeo de revistas político-culturales que apuntalan la incipiente renovación de la esfera pública española, cuyas condiciones de aparición obedecen a las tendencias declinantes del régimen: "por un lado, la crisis de legitimidad del sistema de poder que organizó el franquismo y, por otro, el desarrollo de un mercado para la producción y el consumo de productos de carácter cultural y simbólico" (Pecourt, 2008: 277). Ajoblanco y El Viejo Topo, entre otras, son ejemplos de la proliferación y radicalización dual de alternativas políticas de izquierda y de las revistas donde estas se expresan; evidencian el carácter heterárquico de un escenario cultural con afán democratizador (Pecourt, 2008: 131).

Precisamente desde El Viejo Topo, Félix de Azúa ataca al "grupo de Cardín” y aduce que "son muy académicos, repiten esquemas de los años 68-70. Tel Quel y derivados, Lacan y derivados son pura academia, no es vanguardia" (1978: 45). Igualmente, Juan Manuel Bonet reseña la presentación de Diwan en El País, destacando "lo que puede seguir habiendo de mimético respecto a Tel Quel o Peinture en su actuación" (1978). En un contexto signado por la acelerada modernización del campo cultural, de Azúa y Bonet otorgan al "grupo de Cardín" la colocación distintiva de importador mimético del telquelismo francés. Resulta excesivo en verdad postular la existencia de tal grupo Cardín. Se trata más bien del grupo Trama, exponente principal de la tendencia pictórica pintura-pintura y conformado en 1973 por Jiménez Losantos junto a los pintores José Manuel Broto, Xavier Grau, Javier Rubio y Gonzalo Tena, al que Cardín se ensambla satelitalmente en 1974. Los Trama articulan las muy setentistas "prácticas significantes" mediante, en el plano político, la militancia maoísta en Bandera Roja y, en el artístico, el "retorno 
a la pintura" promulgado por Marcelin Pleynet (Lacruz, 2002: 11). Bregan por la vigencia del cuadro y la abstracción, en línea con el Color field americano y los franceses Supports/Surfaces, frente al conceptualismo y la nueva figuración de fuerte presencia en Barcelona y Madrid.

Yuxtapuestos a publicaciones como Ajoblanco o El Viejo Topo, donde la índole estrictamente cultural se diluye en propuestas omnicomprensivas de transformación social, tanto los órganos de expresión del grupo Trama, Pliegos de producción artística y Trama: revista de pintura, como luego Revista de Literatura y Diwan reivindican como ámbito propio de intervención la especificidad medial y discursiva de la pintura y la literatura, especificidad inextricable de una práctica teóricocrítica de sesgo auto-reflexivo. Pliegos de producción artística es una revista de inclinación maoísta, publicada entre 1974 y 75 por el Cineclub Saracosta de Zaragoza, donde los Trama son pioneros exponentes hispanos de la apuesta programática de Tel Quel:

convertir la teoría de la literatura y la 'escritura' en el espacio privilegiado de la acción política y de la transformación social, [...] [con] un nuevo registro textual que desde el marco literario se constituye como teórico, no siendo por ello ya ni lo uno ni lo otro. (Asensi, 2006: 15-358)

Los Trama dan a conocer en Pliegos traducciones propias de textos de Tel Quel, como La enseñanza de la pintura de Pleynet o las "Tesis generales" de Philippe Sollers. A su vez, la publicación de Trama 0 acompaña la exposición del grupo en la Galería Maeght de Barcelona, cuya introducción-manifiesto dicta la especificidad de su doble propuesta teórico-pictórica:

Toda crítica para resultar efectiva ha de traducirse en la transformación del objeto de su interpretación [...] La pintura y el lenguaje, el discurso que sobre ella versa [...] no puede ser pensado sin la otra y viceversa. (1974: 3)

En 1974 y por fuera del grupo Trama, Jiménez Losantos y Cardín recalan en Revista de Literatura, que contaba con un puñado de números publicados al amparo de la Universidad de Barcelona. Bajo su dirección, Revista de Literatura reorienta su línea editorial y deviene revistaplataforma de actualización teórica: conviven en ella distintos enfoques que hallan en común el afán rupturista por modernizar la escena crítica y literaria española. Amplía y excede el marco telquelista de Pliegos y Trama, al inaugurar vías de diálogo con los referentes neobarrocos de la literatura latinoamericana, con el experimentalismo vanguardista catalán, con las primeras expresiones del psicoanálisis lacaniano en España. A la par que el número 10/11 se inaugura con sendas traducciones de "Locura: madre-pantalla" y "La música y el anzuelo" de Sollers y Kristeva, la concatenación de artículos teóricos, críticos, prosas ficcionales y poemas, sin distinción ni subdivisión interna entre géneros, refuerza la impronta telquelista de su apuesta por la escritura textual. Luego, bajo el título de "Más", este número introduce una entrevista de Cardín a Sarduy, cuyas preguntas exploran los efectos contemporáneos e hispanoamericanos del cruce entre texto y barroco: "Tu introducción en la escritura de variables exóticas y underground, al lado de la cultura clásica, tanto universal como española, ¿supone un intento de atravesamiento simbólico paralelo al trabajo directamente sobre el lenguaje?” (1977: 17).

Por su parte, el número 8/9 de 1976 incorpora un artículo programático y beligerante de Llovet, "Assassinar l'avia (Per una política dels estudis de literatura catalana)", junto a "Dia de la mare" de Biel Mesquida, texto tan inclasificable como tan radical su escritura del catalán: 
"pomamarepatatamarefufamarebetlemmarecotorramarepatatamarerovellómare" (1976: 76). Sumados a la posterior publicación de textos de Quim Monzó y Carles Hac Mor, Revista de Literatura ofrece una muestra representativa de una literatura catalana de vanguardia que hace del experimentalismo textual una toma de partido transgresora y marginal, de cara al proceso de institucionalización y normalización tanto de la lengua como del sistema literario catalán posfranquista (Pons, 2005: 173). Este mismo número apuntala la irrupción del lacanismo en la escena cultural española, irrupción promovida a través de la mediación argentina de Oscar Masotta y reflejada en la transcripción de "Psicosis", conferencia dictada en la Facultad de Medicina de Barcelona y prologada por Cardín. La presencia del psicoanálisis lacaniano se acentúa con artículos como "Comentarios a 'La Gradiva de Jensen”", de Cardín; "Psicoanálisis, literatura, crítica”, de Alex Sáez; y "Freud, de turismo en España”, de Jiménez Losantos.

En 1978 y tras la clausura de Revista de Literatura, Cardín y Jiménez Losantos impulsan una publicación propia, asociada a Alcrudo Editor de Zaragoza: Diwan. Meses antes del lanzamiento, la contratapa de Trama 1/2 anuncia su pronta aparición bajo el título Diwan: cuadernos de crítica y cultura. Si bien el subtítulo es finalmente descartado, expone su opción por la especificidad de la labor crítica, amplificada y acentuada en la polisemia del propio nombre de la revista: en la cultura islámica, el término diván hace referencia a colecciones de poemas de un mismo autor; de allí toma su título el poemario de García Lorca, Diván del Tamarit, etimológicamente, en árabe, diwan es la sala donde el sultán celebra sus consejos; por último, la obvia y directa referencia al diván psicoanalítico. De este modo y a lo largo de cuatro años de publicación, Diwan articula su programa crítico-literario a partir de un doble eje: relectura de la tradición literaria hispana y decidida apuesta por la renovación teórica provista por el psicoanálisis lacaniano. Ambas vertientes encausan una misma voluntad de intervención en el campo cultural de la transición, orientada a interrogar los roles en él desplegados por la literatura y por la figura del intelectual.

En el prólogo a la reedición de 1995 de su libro Lo que queda de España, Jiménez Losantos reconstruye las circunstancias que rodean la iniciativa de Diwan. Sostiene que Diwan plasma su propia búsqueda por contraatacar el auge posfranquista de señas de identidad y nacionalismos periféricos, por llevar adelante una reivindicación españolista de signo republicano y responder al "problema de España" con la relectura en tono liberal de la tradición intelectual del exilio:

Diwan quiso trazar el rumbo de una política cultural liberal en una generación y en un país dominado por el marxismo más o menos descafeinado, por el izquierdismo cosmético, por la negación de lo español. (1995: 114)

Diwan refleja tal empresa intelectual tanto en la merma de firmas catalanas, con tan solo una única contribución de Biel Mesquida en Diwan 1 ("Babel catalana, on no ets?"), como en la elocuente presencia de ensayos matizados de interpretación nacional. El primer número de la revista evita la nota editorial para en cambio inaugurarse con "El desdén con el desdén: Manuel Azaña"; Jiménez Losantos postula allí un alegato en clave cultural por la nación española y traza continuidades entre el estilo literario de Azaña y su inscripción ideológica como presidente de la II República. En esta línea, Jiménez Losantos publica artículos como "Unas cuantas disidencias con Juan Goytisolo" y "Por la calle de Unamuno", en Diwan 2/3 y 10, respectivamente, mientras que Cardín hace lo propio con "Suite Española" en el número 5/6. 
Con la inclusión y adhesión en el número 2/3 al manifiesto del CIEL (Comité de Intelectuales por la Europa de las Libertades), Diwan replica en la escena cultural española el "giro a la derecha" que en Francia emprenden los máximos exponentes de Tel Quelt. En este mismo número de Diwan, el dossier homenaje a Lezama Lima enfatiza el interés continuado por los ecos transatlánticos y consiguiente redefinición hispanoamericana del barroco, ya entrevisto en Revista de Literatura y luego repetido con sendos "Especial Barroco" I y II en Diwan 5/6 y 8/9. Si por un lado, como afirma Jiménez Losantos, la yuxtaposición de manifiesto y dossier "subraya la españolidad, la universalidad y el liberalismo militantemente antitotalitario de nuestra revista" (1995: 62), la figura de Lezama, por otro, habilita la conjunción de barroco y psicoanálisis lacaniano, luego explorada por Sarduy en "El barroco après la lettre" y por la cohorte argentina ligada a la revista Literal, cuyas firmas pueblan el "Especial Barroco II" con una selección de textos de Macedonio Fernández y contribuciones como "El oxímoron barroco" de Germán García, "Barroco y sus hermanos" de Eduardo Grüner, "Lacan barroco: ¿deriva o desvarío?” de Sara Glasman y “Góngora y el estilo castellano ¿llano?” de Luis Gusmán. Los vínculos personales e intelectuales entre los comités de redacción de Diwan y Literal, principalmente entre Cardín y los emigrados García y Glasman, habilitarían pensar el "Especial Barroco II" como una "una suerte de imaginaria Literal 6/7, [...] [que] cobija entre sus páginas la diáspora de Literal' (Mendoza, 2011: 13). Tal impronta argentina expone la apuesta de Diwan por "sacudir" la teoría y crítica literaria local mediante la esgrima provista por el psicoanálisis lacaniano. Mientras García traduce el soneto "Hiatus Irrationalis" de Lacan y firma "Lacan, de otra manera" en Diwan 12, el número 2/3 también incorpora "La represión: lo no dicho y el decir", de Glasman, seguido por "El juego de Michel Foucault", transcripción de su acalorado debate con la revista francesa y lacaniana Ornicar?

De esta manera, la revisión de nombres y artículos publicados durante los cuatro años de Diwan permite tensionar y exceder los alcances del recuento retrospectivo de Jiménez Losantos, quien limita la revista a ser enseña de su propio proyecto de renovación españolista. Sin embargo, las imputaciones de telquelismo mimético de de Azúa y Bonet se repiten llamativamente en posteriores prologuistas de la obra de Cardín: mientras Delgado presenta ambas revistas como "delegaciones locales de Tel Quel, Promesse o Peinture" (1997: 18), Castro categoriza a Diwan como "revista telqueliano-lacanaiana" (2016: 11). Ahora, si bien Tel Quely sus figuras señeras puntúan la evolución política de Cardín y Jiménez Losantos, desde el sesgo maoísta de Pliegos de producción artística hasta el acendrado liberalismo del CIEL, las propuestas textuales de Revista de Literatura y Diwan transitan una temporalidad propia y distintiva. Se atenúan las tempranas traducciones de Kristeva, Pleynet y Sollers, con una única inserción, en el "Dossier Céline" de Diwan 7, de dos artículos de Kristeva. A su vez, mientras Revista de Literatura sigue un esquema de indiferenciación interna entre géneros afín a la escritura textual de Tel Quel, Diwan estructura sus números mediante una clara distinción entre secciones propiamente literarias, teóricas y críticas, reflejo de su programática apuesta por la especificidad discursiva del ensayismo crítico. El recurrente interés por el barroco, además, brinda una decidida impronta hispanoamericana al empeño teórico por explotar nociones como texto y escritura. Referentes como Lezama Lima y Sarduy convierten a

\footnotetext{
${ }^{4}$ Hacia 1975, tras la controversia suscitada por Archipiélago Gulag de Soljenitsyn y la "desilusión” del viaje a China, Tel Quel se distancia del maoísmo y asume programáticamente la reivindicación del individuo frente al totalitarismo.
} 
Revista de Literatura y Diwan en exponentes hispanas del fenómeno de "telquelismos latinoamericanos" enunciado por Wolff: los indiscutibles lazos con Tel Quel exceden el mimetismo o la dependencia para afirmarse desde el "entre-lugar" híbrido de una apropiación creativa y en diálogo con coordenadas político-culturales vernáculas (2009: 35).

El "telquelismo hispano" de Revista de Literatura y Diwan revela así su traza diferencial en el campo cultural posfranquista: su introducción pionera del psicoanálisis lacaniano, con mediación argentina de Masotta y junto a la inflexión barroca de su programa estético, inauguran apuestas intelectuales irreductibles a toda catalogación de mimetismo francés. Revista de Literatura y Diwan configuran entonces un espacio textual estrábico, que aspira a producir una intervención críticoliteraria en el contexto español inmediato mientras persigue sus interlocutores teóricos a ambos lados del Atlántico. El destacado rol que Cardín y Jiménez Losantos reconocen en Masotta, sumado al intercambio de firmas y contribuciones establecido con Literal, ofrece la oportunidad de des-españolizar y suscitar renovadas aristas de lectura del período transicional, de hallar en este entrelazado textual transatlántico una vía posible de respuesta a interrogantes comunes.

\section{MASOTTA, ¿FUE GARDEL?}

"Masotta, ¿fue Gardel? Era otra época, me digo, allá por el 70 estudiábamos Lacan”, dice Osvaldo Lamborghini en Sebregondi se excede. Lacan y los setenta, marca de época cuyos ecos porteños reverberan en el interés exhibido en la España posfranquista por el psicoanálisis. Por un lado, forma parte de la revisión de una disciplina psiquiátrica funcional al aparato biopolítico dictatorial, dominada por lineamientos higienistas, cuando no católicos y filo-fascistas (Cayuela Sánchez, 2010: 248). Emerge junto a manifestaciones tan rupturistas como la difusión de Ajoblanco de autores como David Cooper y Félix Guattari y, en el ámbito clínico, la acción de colectivos antipsiquiátricos en áreas como el Hospital Clínic de Barcelona (Ribas, 2017: 489). Por otro lado, el psicoanálisis tributa su dosis de seducción a los impulsos modernizadores de la escena literaria española: escritores y críticos se abocan a la puesta al día con los "tiempos dorados" del formalismo y el (pos)estructuralismo. Modernización que no halla cabida en el marco de unos estudios literarios de excluyente cuño filológico-positivista, sino que procede a través de canales laterales a la institución universitaria (López, Talens y Villanueva, 1994: X).

Tras su exilio de Argentina, Oscar Masotta se establece en Barcelona y da inicio a sus grupos de estudio privados de la obra de Lacan en octubre de 1975. Figura paradigmática de los itinerarios culturales argentinos a lo largo de tres décadas, Masotta comienza su labor crítica alineado con el existencialismo marxista y sartreano de la revista Contorno, en los comprometidos años cincuenta, para luego promover el análisis estructuralista y semiótico del arte pop y de vanguardia, en los swinging sixties locales, y finalmente ser el pionero en la introducción del psicoanálisis lacaniano desde comienzos de los setenta. Sea en grupos de estudio como más tarde en la incipiente Escuela Freudiana de Buenos Aires, la enseñanza lacaniana de Masotta responde a una condición de doble marginalidad institucional. Primero, resulta exterior al ámbito propiamente clínico del psicoanálisis, por entonces bajo autoridad de la Asociación Psicoanalítica Argentina. Luego, los grupos de Masotta participan de un fenómeno de amplio alcance en Buenos Aires, ligado a la irrupción de espacios alternativos y para-institucionales de circulación de saberes, por fuera de una universidad intervenida por el gobierno militar en 1966. Tal como 
reconstruye su ladero Germán García:

Sus viejos amigos no pueden creerlo. Masotta —el de la crítica literaria, el de la polémica con la revista Sur sobre el peronismo, el organizador de la primera bienal de la historieta, el teórico del happening — se ha convertido en la cabeza visible de una pandilla que polemiza con la izquierda y pretende discutir la 'natural' pertenencia del psicoanálisis al campo de la medicina. (2005: 237)

Dadas tales coordenadas contextuales, y sumadas a la propia extracción literaria de la trayectoria intelectual de Masotta, no es la práctica clínica institucionalizada sino el campo cultural quien primero y con mayor vigor expresa los efectos de la "entrada" de Lacan en Argentina. Desempeña un rol decisivo la revista Los Libros (1969-76), principal exponente e impulsora de la modernización teórica y metodológica con que la crítica literaria argentina, a través de nombres como Josefina Ludmer, Nicolás Rosa y Noé Jitrik, incorpora al psicoanálisis como parte de un instrumental capaz de delinear una hasta entonces inédita especificidad "cientificista" de la crítica. Luego, la ya mencionada Literal (1973-77), liderada por escritores cercanos al entorno de Masotta como García, Lamborghini y Gusmán, se erige como revista vanguardista por excelencia e icónico espacio de intersección entre literatura y lacanismo. Literal aspira a intervenir polémicamente en el escenario político-cultural argentino desde la "inutilidad y gratuidad" de la literatura (Giordano, 1999: 60), dando forma a una apuesta programática que "denuncia la coartada de un campo literario ahogado por las demandas políticas y propone, en lugar de una literatura revolucionaria, una revolución de la literatura" (Idez, 2010: 13). La materialidad de la letra, la conjunción entre escritura y goce, entre exceso y resto, hacen de este "lacanismo de combate" la más distintiva cifra de una apuesta político-literaria de negatividad radical (Crespi, 2011).

El arribo a Barcelona de Masotta y otros psicoanalistas argentinos exiliados encuentra en la apertura cultural posfranquista un medio favorable a la difusión de un lacanismo ausente en el panorama español. Señala Catelli, sin embargo, el desfasaje entre el aura de novedad cultural y la escasa inserción institucional con que el discurso lacaniano es a la par recibido en España:

ni la llegada de las traducciones desde Argentina, ni la de los exiliados más tarde, alteró masivamente el funcionamiento institucional, [...] reticente a la incorporación del discurso psicoanalítico como herramienta cultural y como recurso clínico. (2017: 12)

Por su parte, Druet describe los límites disciplinares con que los círculos psicoanalíticos por entonces activos en España, minoritarios y vinculados a la psiquiatría franquista, restringen el impacto propiamente clínico de la tendencia lacaniana:

los dos círculos pertenecientes a la IPA los integraban muy pocos miembros, casi todos ellos psiquiatras o psicólogos. Tenían un crecimiento muy lento y dedicaban la mayor parte de sus esfuerzos a la vida institucional y a la formación de los pocos candidatos que aceptaban. (2017: 65)

La efervescencia político-cultural, el boom editorial de los primeros años de la transición, llevan a sectores intelectuales y estudiantiles a demandar la puesta al día de la teoría psicoanalítica vernácula con las corrientes de pensamiento más agitadas de la época. Un discurso hasta entonces marginal, el psicoanálisis, irrumpe asimismo desde el margen, ante la ausencia de 
espacios institucionales capaces de dar respuesta a esta demanda. Los seminarios de Masotta se constituyen en núcleos de vanguardia, donde el lacanismo invita a radicalizar los postulados de un amplio arco de propuestas intelectuales, desde la psicología al activismo político y la literatura.

Las primeras expresiones del lacanismo en España encuentran entonces, en actores y medios del campo cultural, mayor eco que en instituciones clínicas o universitarias. Las circunstancias que rodean la introducción del psicoanálisis lacaniano en Argentina y España exhiben un cierto aire de familia que explica el impacto y efectos de la figura de Masotta en ambos continentes: proveniente del ámbito de la literatura, reúne a otros literatos e intelectuales en grupos de estudio que, desde canales marginales y para-institucionales, no solo bregan por la entrada del discurso lacaniano en las esferas clínicas del psicoanálisis, sino que además asimilan sus postulados teóricos y hacen de estos un catalizador de distintas propuestas artísticas y críticas, cristalizadas en publicaciones como Los Libros, Literal, Revista de Literatura y Diwan.

\section{LAS ARMAS DE LA CRÍTICA}

Presenta Cardín a Masotta en 1978 como "uno de esos personajes teóricos, en modo alguno habituales en la cultura peninsular y bastante abundantes al parecer en Argentina" (1993: 23). La teoría como atributo distintivo de una determinada postura intelectual, delineada por el propio Masotta en su prólogo a Conciencia y estructura, recopilación de sus escritos críticos de corte existencialista, psicoanálisis y arte pop. Masotta acuña la idea de "intelectual teórico" en tanto lógica explicativa de tal desplazamiento entre intereses y referencias de pensamiento:

Ni ocupándome de las obras de los artistas pop traiciono, ni desdigo, ni abandono el marxismo de antaño [...] Lo que ha cambiado tal vez es la manera de entender el rol del intelectual en el proceso histórico: cada vez comprendo más hasta qué punto ese rol tiene que ser 'teórico'; esto es, que si uno se ha dado la tarea de pensar, no hay otra salida que tratar de hacerlo lo más profunda, lo más correctamente posible. ¿Podrá alguno alguna vez cumplir con esta exigencia elemental? (2010: 30)

Repara en este pasaje Diego Peller y halla en él la singularidad de la "pasión por la teoría", noción con la que aborda el sesgo teorizante desplegado por la crítica literaria argentina durante las décadas de 1960/70. Tal "exceso" y "pulsión” teórica no se plasma en obras que, por derecho propio, pertenecerían al género estricto de la "teoría literaria", sino que se expresa, en autores como Masotta o las ya mencionadas Los Libros y Literal, diseminado y contaminando territorios discursivos limítrofes como la ficción y la crítica, e incluso prólogos y entrevistas. La "exigencia elemental" expuesta por Masotta, el imperativo por dar cuenta de su trayectoria intelectual, configura para Peller a la pasión teórica como un gesto auto-reflexivo, como el pliegue sobre sí mismo de un sujeto crítico que, paradójicamente, reafirma su instancia enunciativa a través de la propia puesta en crisis: "el sujeto crítico se sitúa así en el lugar de una carencia o de una precariedad de la institución crítica y la 'suple' con un gesto memorialista” (2016: 120). La crítica afirmaría así productivamente su propia carencia de inserción institucional, mediante una pasión teórica que es, necesariamente, pasión por el sujeto: su operación crítica fundamental consiste en la "autofiguración textual del crítico, que al escribir su texto, se construiría a sí mismo como sujeto; pero además, por un movimiento 'auto-reflexivo' propio del discurso teórico, discutiría esa operación constructiva, sus condiciones, sus límites” (2016: 117). El sello distintivo del 
"intelectual teórico" se plasma en el exceso de una afectación auto-reflexiva radical, en el hiato entre el sujeto y su "propio lenguaje" que solo la teoría permite instaurar, en tanto dispositivo de distanciamiento crítico: "solo hay puesta en cuestión extrema, incondicional del sujeto, desde la distancia radical de sí a sí, desde la división interna que solo pudo articularse en los términos teóricos del psicoanálisis lacaniano y la lingüística estructural” (2016: 324).

El intelectual teórico de Masotta configura a su vez su singular concepción de la crítica literaria:

un ejercicio -violento, agonístico, polémico- de develamiento de las intenciones -inconfesadas, inconscientes- del autor. Este ejercicio sigue dos métodos: develamiento ideológico (cuando se trata de la obra de otros), confesión y autoexamen (cuando se trata de la obra propia). (Peller, 2016: 72)

Por ejemplo, en 1958 publica "Explicación de Un dios cotidiano", ensayo crítico donde deconstruye el "ser uno mismo" que David Viñas exhibiría en su integridad de escritor comprometido y denuncialista: "La desgracia de los hombres íntegros es que tarde o temprano terminan descubriendo que, [...] en cambio de ser uno, ellos son, desde el comienzo, dos" (2010: 162). La conceptualización lacaniana del sujeto escindido deviene en Masotta recurso polémico de desmontaje de (im)posturas intelectuales. Repite la operación en "Anotación para un psicoanálisis de Sebreli", de 1967, donde acusa a Juan José Sebreli de "escritor fascinado por su ilegitimidad" y señala los procedimientos retóricos con que este intentaría autorizarse como instancia de opinión, los "mecanismos por los cuales pretende, a cada paso, legitimar [...] los productos borrosos de aquella ilegitimidad" (2010: 253). Método analítico que Masotta revierte sobre su propia figuración como sujeto crítico en "Roberto Arlt, yo mismo", donde interroga las circunstancias intelectuales y personales que rodearon la escritura de su propio ensayo Sexo y traición en Roberto Arlt.

si es cierto que los productos de la actividad individual no se separan de la persona, podría hacerme esta pregunta: ¿quién era yo, entonces, cuando escribí ese libro?; y también: ¿qué pienso yo en el fondo y de verdad sobre ese libro? (2010: 224)

El ademán auto-reflexivo de la pasión teórica impregna así textos críticos donde la polémica es tanto voluntad de intervención como estrategia de lectura y motor formal del propio discurso. Como señalan Jinkis y Giordano, teoría y polémica constituyen en Masotta dos momentos inextricables de un mismo gesto crítico: "Primero descubrir el 'error' en el otro, y después, como ese error solo puede serlo en relación a una teoría, construir la teoría que ese error supone y que muy regularmente es inadvertida para el propio autor" (Jinkis, 1984). La lectura sintomática de Masotta apunta a develar la verdad del error, verdad entredicha en el lapsus de su interlocutor y que remite a la instancia enunciativa del sujeto crítico: "vuelve sobre lo que acaba de decirse para situar la discusión en el nivel que él supone más riguroso: el de las condiciones de enunciación" (Giordano, 2005: 144). En su libro El modelo pulsional, dedicado a revisitar los conceptos fundamentales del psicoanálisis, Masotta define su propia empresa de relectura del corpus freudiano como "pedirle a un texto que hable sobre aquello que casualmente decide no hablar" (1990: 64). En aquel lugar vacío, tal como se sigue de sus críticas a Viñas, Sebreli y sí mismo, residen el sujeto y las condiciones de enunciación, a las que convierte en objeto del 
enunciado e interroga mediante un auto-reflexivo pliegue teórico. No qué dice, sino desde dónde y qué hace alguien cuando dice eso. Como sostiene Lacan en "El atolondradicho", "el decir queda olvidado tras lo que se dice en lo que se escucha” (2013: 477). Restitución, en lo dicho, del decir: dictum que sintetiza y cifra la especificidad de la crítica según Masotta, especificidad que Cardín enriquecerá con operaciones propias de lectura y escritura en Revista de literatura y Diwan.

Revista de Literatura 8/9 presenta la mencionada conferencia "Psicosis", donde Masotta recurre a una anécdota planteada por Lacan en sus Escritos y extrae una sentencia que Cardín más tarde convierte en enseña e impulso de su escritura crítica: "un insulto realiza su función primera, que es la de otorgar identidad. Si usted duda de quién es usted, nada mejor que el insulto del otro para ubicarlo a usted en sus cabales" (1976: 32). Similarmente, en Diwan 5/6 Cardín reseña La batalla en torno a Góngora (1978), compilación de textos belicosos y polémicos de los grandes nombres del Siglo de Oro en torno a la publicación de Las Soledades. Dice Cardín:

Admírense ahora quienes hablan de modos tabernarios [...] Vean al Fénix de los Ingenios mostrando su despecho ante Góngora y llamándolo ridículo. Vean al cojo manchego tomando ventajas ideológicas frente al galano canónigo, con lo que más podía doler entonces: tratándolo de judío. Aprendan lo que eran panfletos y golpes bajos, bulos y libelos. Todos ellos, eso sí, compuestos en el más florido y cuidado estilo, que precisamente sacaba su fuerza del personal enojo y de la envidia. (1979: 134)

Cardín halla en estos clásicos del Siglo de Oro una contraposición a su propio campo cultural, un espejo invertido donde reflejar su propia marginalidad ante el reacomodamiento intelectual de la transición: "vienen a decirnos los pequeños sátrapas, criados al socaire del franquismo y elevados al rango de intocables, [...] vienen a llamar ahora fascistas a los que, con más comedimiento que los genios que aquí se ofrecen, los atacan para poder construir su propia escritura" (1979: 134). Frente al tablero consensual delineado por medios como El País, y al amparo del cual los intelectuales establecidos replicarían en clave cultural la transición política "pacíficamente" dirigida por las élites partidarias, Cardín reconoce en el insulto, tal como dictamina Masotta, un medio de situar e interrogar el acto del decir, de develar las condiciones enunciativas subyacentes a los enunciados de sus siempre denostados "pregoneros":

Hay en el insulto una interrogación a la persona misma y a lo escrito, que tiene categoría de crítica cuando da en el blanco. Y da en el blanco siempre que despierta la ira. Si de esta ira y ese insulto surge una prosa cargada de rigor, nunca la lengua quedará más agradecida. (1979: 135)

La reseña de Cardín condensa un programa de escritura tanto formal como político, que ubica en el insulto un recurso literario capaz de trocarse en posicionamiento intelectual, de hacer de su colocación marginal una dual e indisociable voluntad de estilo y de intervención polémica. Diwan alberga una especie de sub-revista, un proyecto emprendido por Cardín e inicialmente destinado a conformar una publicación diferenciada y por derecho propio, titulado primero "Minima et varia" en Revista de Literatura 10/11 y luego "Otrosí: diario de lecturas" a partir de Diwan 1. "Otrosí" reúne breves intervenciones críticas inspiradas por el día a día de la escena cultural española, con explícito objeto de contradecirlo todo y publicitadas por el propio Cardín como "la cosa más desvergonzada del país, que no deja títere con cabeza. Cardíacos abstenerse. 
Universitarios prepararse" (1979: 26). Una célebre cita de Marx y una pequeña viñeta ilustrativa anteceden la presentación inaugural de la sección en Revista de Literatura 10/11:

Es cierto que el arma de la crítica no puede sustituir a la crítica de las armas, que el poder material tiene que derrocarse por el poder material, pero también la teoría se convierte en poder material tan pronto como se apodera de las masas. Y la teoría es capaz de apoderarse de las masas cuando argumenta y demuestra ad hominem, y argumenta y demuestra ad hominem cuando se hace radical (1977: 137).

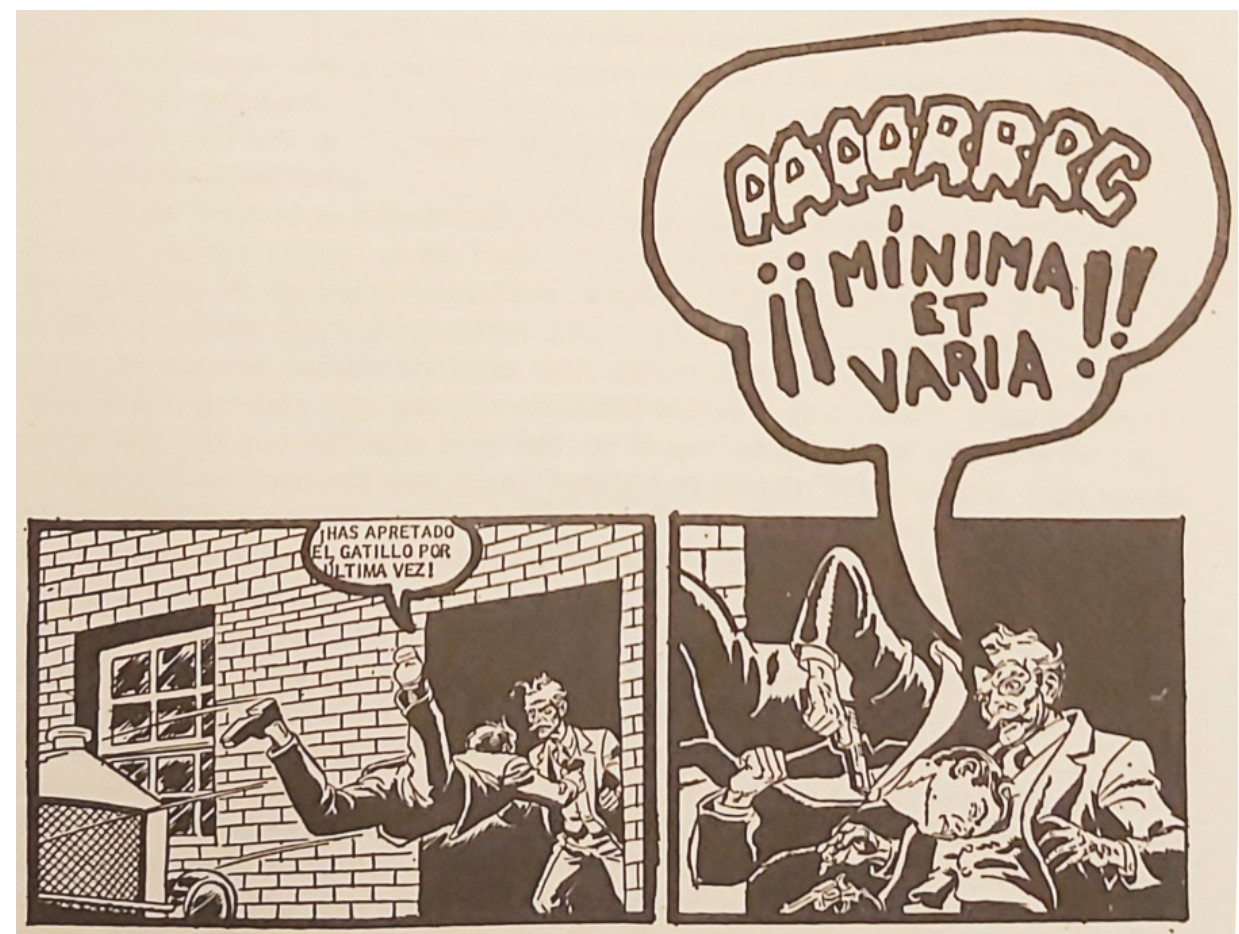

Radicalidad teórica y argumentación ad hominem, ejes programáticos del proyecto crítico emprendido por Cardín: en estas armas de la crítica encuentra los recursos con los que practicar una teoría lanzada "de cabeza", con los que llevar adelante intervenciones polémicas capaces de hacer, según el imperativo analítico entrevisto en Masotta, de las condiciones de enunciación el objeto del enunciado. "Otrosî" reúne una serie de textos desarrollados bajo la forma de feroces y relampagueantes respuestas - no solicitadas, desde ya- a publicaciones o declaraciones públicas recientes. En su primera entrega, Cardín arremete contra "Frankenstein-Trías" (Eugenio Trías) por "recubrir de ludismo lo que no es más que ignaro vuelapluma", contra "Jetanguren" (José Luis López Aranguren) por "pasearse por todos los ruedos del saber", contra "San Terencio Mártir" (Terenci Moix) por "transportar los santos corporales por la Roma imaginaria de la nueva escenografía gay", contra "Fray Tierno" (Tierno Galván) por "chocho ya, seguir con su cantinela monástica, rupestre". ¿Con qué impunidad y a cuántas grandes y unánimes figuras de la intelectualidad progresista institucionalizada puede atacar un personaje liminar como Cardín, desde una revista decididamente minoritaria y hoy olvidada como Revista de Literatura? Donde no hay oponente, Cardín se lo inventa y halla, en el insulto y la discusión, el modo no solo de desplegar su escritura, sino también de construir su audiencia. Lleva adelante, de este modo, una 
política de la lectura: convierte el comentario bibliográfico en arena de lidia donde la mayor o menor idoneidad para ejercer la crítica decidirá la suerte de posiciones enunciativas contrapuestas.

Entre tales personalidades del establishment cultural posfranquista, a las que Cardín destina un sinfín de textos e invectivas, es Fernando Savater su gran némesis, el blanco predilecto de sus diatribas. A la luz de su trayectoria, Savater es catalogado como "intelectual de mayor éxito en la democracia" (Plata Parga, 2010), "figura de la disidencia institucionalizada" (Imbert, 1986) o "intelectual mediático por excelencia" (Morán, 2014). Su Panfleto contra el Todo conforma un "contratexto" de la Constitución de 1978 (Buckley, 1996: 79), una denuncia del velo ilusorio con que la renovada y fetichizada democracia enmascararía sus continuidades con el poder opresivo del franquismo: “Cambiarlo 'todo' equivale, según parece, a cambiar de Todo, [...] nada se parece tanto a un Todo como otro Todo" (1978: 77). El anarquista Savater homologa el Todo a las instituciones de la democracia representativa, frente a las que reivindica la soberanía inalienable del individuo. La verdadera revolución acabaría con la delegación del poder político y sería impulsada por los "nuevos marginados", feministas, homosexuales, prostitutas, presos o drogadictos, quienes "sienten en carne viva que la Ley del Todo les es contraria” (1978: 81).

En Diwan 5/6, Cardín comenta La sociedad contra el Estado de Pierre Clastres a fin de extrapolar la crítica y señalar los ecos de este autor en el Panfleto de Savater. Hace de la reseña un instrumento mediador con el que atacar la noción fetichizada de estado que subyacería al Todo: “por más que se esfuercen en [...] difuminar de 'Todo' el 'Uno' personales que se les aparece como opresivo espectro personal. Lacan diría que no han logrado metaforizar al Padre" (1979: 156). Replica esta operación de reseñismo mediador y de combate en Diwan 7 , donde recurre a Los nuevos nacionalismos en Europa de Tom Nairn para impugnar la "Teoría del nacionalismo performativo" acuñada por Savater. Celebra el riguroso método de Nairn, el cual opone a la "ingenuidad y mala fe" de un Savater que convierte al nacionalismo vasco en foco de resistencia al Todo: "ha inventado un nacionalismo eiusque generis que se realiza con solo hablarse, lo cual viene a ser otro más de sus maravilloso inventos [...] doblemente paradójicos y doblemente ridículos" (1980: 118). Tal como la lectura sintomática de Masotta, Cardín apunta al lapsus de Savater y expone en él la verdad del error, reconstruye la teoría que aquel error supone:

Savater no distingue entre 'inlocución' y 'perlocución'. Su definición de performación parece más bien querer referirse a la perlocución, pero esto no invalidaría mi crítica, ya que la perlocución pretende que algo ocurra, $[. .$.$] por lo que el acto sigue siendo interno al$ lenguaje. (1980:119)

Es la publicación de La infancia recuperada, primer best seller de Savater en 1976, excusa disparadora de su más encendido intercambio con Cardín. La infancia recuperada participa de un cierto espíritu de época, cuando distintas producciones artísticas españolas apelan a los encantos y temores de la infancia como antídoto ante la monotonía y los impasses del principio de realidad de la transición (Labrador, 2017: 3415). Entre exponentes como El espiritu de la colmena (1973), Cría cuervos (1975) o Arrebato (1980), Savater reivindica la pasión por la fábula, por el "nivel ético de la narración" con que el relato de aventuras inspira ansias de libertad y valores heroicos. Contra la "timorata corrección de las costumbres", Savater invita a la rebelión de la imaginación, tras cuya victoria "volverán a ondear juntas las dos banderas del alma rebelde", la roja de Sandokán y la negra del capitán Nemo (1994: 112). Anarquismo y aventura confluyen en esta 
reivindicación del placer por la lectura de "historias narradas", entre las que cuenta a Jack London, Jules Verne o R.L. Stevenson, a quienes no solo asocia a las conmociones de la infancia, sino que además opone al sesgo teórico y vanguardista de la crítica literaria en boga:

me gustan esos narradores por las mismas razones que a los niños, es decir: porque cuentan bien hermosas historias, que no conozco razón más alta que esta para leer un libro, y que en literatura me paso siempre que puedo de sociologías y psicoanálisis, para que el hígado no se resienta. (1994: 20)

Con "De estirpe de augustos" en Revista de Literatura 10/11, Cardín refuta en Savater una idea de infancia tan fetichizada y arribista como aquellas de Todo o de nacionalismo performativo. Acusa a Savater de "ludismo prematuramente chocho", de obviar la disposición freudiana del niño como perverso polimorfo, de no comprender "los abismos de negrura" detrás de estos autores y de reivindicar por ello ingenua y oportunistamente a la infancia como edad feliz:

Igualando a los niños con las pasiones sublimadas de los adultos melancólicos [...] infantilizan su relación a la política [...] Odian al Un-padre porque este coarta su omnipotencia infantil frustrada, y ofrecen a los niños esta misma frustración como alternativa. (1977: 141)

Entre infancia y Todo, Cardín ubica en el "único y stylístico Savatrágalas" dos caras de una misma imposibilidad, cuando de dar cuenta de la trabazón entre enunciado y enunciación se trata:

Entre tanta epopeya que nada quiere saber de Propp, ni de Sollers, porque en su sofisticación destruyen el goce primitivo, Micer Savatrágalas discurre la forma de criticar lo existente conservándolo, del mismo modo que su unicidad pretende conservarse tras la destrucción del Estado. Así, jugando juegos de ancianos que pretenden volver a una infancia que nunca existió, conserva la ilusión en el aburrimiento cotidiano, de igual modo que los niños entre palo y palo se imaginan ser el Capitán Hatteras, o el mismísimo Tigre de Mompracem que cada semana pueden visionar en TVE. (1977: 142)

Desde la interrogación teoricista de Cardín, la postura anti-teórica de Savater excede la mera opinión literaria para en cambio y necesariamente responder a una posición enunciativa conforme a la doxa político-cultural. Más allá de las osadas palabras de "Savatrágalas" en sus libros o columnas, de todo deseado heroísmo infantil o subversión libertaria, su propia condición de celebrity intelectual no podría sino abonar a la normalización del campo cultural posfranquista. Cardín repara en las "lagunas" conceptuales del radicalismo ideológico de Savater, las que no serían mera anécdota sino que resultarían consustanciales a su impostura, subterfugio maximalista de un íntimo rechazo a rever su propio rol en el devenir institucional de la transición, a cuyo afianzamiento contribuiría con su inocuo modo de "criticar lo existente conservándolo".

La réplica de Savater acontece desde El Viejo Topo 29, donde con "Filosofía y "haute couture" cataloga a Cardín de "modistilla", obvia referencia a su condición homosexual y al paralelo nominal con el modisto Pierre Cardin. Extiende el menosprecio a la misma Diwan: "del doctor Lacan a los trabajosos chismorreos tal cual que Tel Quel, cabe todo, sin faltar algún ilustre nombre de modisto acompañado por gustos de modistilla" (1979: 20). El desprecio hacia el "chismorreo" francés aúna persona y estilo, a la par que replica las acusaciones de telquelismo mimético: "la jerga compone modelos exclusivos para iniciados, confeccionados por dogmáticos 
modistos" (1979: 20). Las descalificaciones de Savater escalan metonímicamente desde Cardín hacia Tel Quel, deteniéndose en Revista de Literatura y Diwan en tanto "revistas de colegio", inocuas publicaciones de desproporcionada ambición polémica, ilegible "calembour" escritural y vanguardismo aspiracional: "Su agresividad es una vocación de espina que se toma por espada; [...] nunca lograrán verse como lo que son, oritguitas y cardines" (1979: 20).

Si, como afirma Masotta, "nada mejor que el insulto del otro para ubicarlo a usted en sus cabales" (1976: 32), Cardín responde a Savater en Diwan 4 con "¡Pero qué gran lector eres, Savater!" y "Fealdad y filosofía", dos textos donde transmuta al insulto de arma de ataque en medio de defensa. Cardín se apropia del sitio de enunciación delineado por epítetos como "dogmático modisto" y "tal cual que Tel Quel”, para desplegar desde allí un gesto crítico capaz de hacer de la impronta teoricista un contraataque bivalente, de encontrar en la propia relación con la escritura una determinada toma de posición ante al escenario intelectual español:

Estilo de "calembour", dirá sin duda Savater de este en que escribo, pero ¿qué le vamos a hacer? [...] Para que luego se diga que no se nos entiende, y que somos esotéricos, y que mucho Lacan y mucha mandanga rara, con lo cristalino que hace remedar a Cioran y a Nietzsche en estilo de tres a chavo para llenar cuatro cuartillas. (1979: 199)

La resistencia de Savater a la teoría es traducida en la escritura crítica de Cardín por la propia resistencia de la teoría, por el pliegue autorreflexivo con que la "pasión teórica" interroga el acto del decir subyacente a lo dicho. Cardín enarbola su condición de "modistilla" y revierte tal invectiva sobre el sujeto intelectual configurado por Savater: "que en el debate cultural se argumente ad hominem, fundándose no precisamente en la miseria sexual que la filosofía de cada uno encierra, sino en lo que los textos de cada uno dicen de la respectiva identidad" (1979: 221). Cardín impugna en Savater una lógica argumental que clausura en su enunciación aquella misma apertura que sus enunciados pretenden fomentar: "miran los lúdicos reformados los bajos placeres del mundo como un submundo que no merece sus afanes filosóficos, pero que deben adoptar como coartada [...] para mayor difusión de todos y beneficio propio" (1979: 223). Cardín apunta a desestabilizar la instancia enunciativa de un Savater que, mientras alega reivindicar a feministas, homosexuales y presidiarios como focos de subversión ante el Todo, luego se erige en autoridad capaz de despreciar y jerarquizar voces mediante el sexista apelativo de "modistilla":

¿Quién desde una postura que dice rechazar La Verdad puede establecer una jerarquía entre modistos, sastres y modistillas, sin tomar en cuenta el discurso que cada uno pueda producir? Nada que mejor defina la fealdad en filosofía que tan vana prepotencia. (1979: 224)

Frente a propuestas de máxima como el Panfleto de Savater, para Cardín la crítica hace política cuando problematiza y desmonta toda ilusión de continuidad tranquila, de identificación narcisista e imaginaria entre enunciados y condiciones de enunciación, entre, por ejemplo, radicales proclamas revolucionarias y confortable reconocimiento institucional. Ante el reordenamiento que la transición supone para el campo cultural posfranquista, Cardín despliega sus intervenciones críticas siempre en discusión, hallando en el insulto y la polémica el medio de exponer y sacudir las reglas del juego. Como dice Germán García sobre el afán crítico de Masotta, donde parece entablar una guerra de enunciados en verdad expone y disputa una plataforma de enunciación: "no importa tanto lo que opina cada uno, sino quién impone aquello 
sobre lo que se debe opinar" (2018: 223). Para Cardín, el permanente ataque y defensa ad hominem fuerza a los intelectuales a dar cuenta de sus propias condiciones de enunciación, revelando así las disputas subyacentes por "imponer el tema", por definir de qué y cómo se habla en el campo cultural. En "Otrosí" y tal como enseñan sus ataques a Savater, Cardín exhibe una vocación de intervención polémica respecto a publicaciones recientes y "de moda" en el escenario intelectual español: con su método de lectura atenta y sintomática, localiza en la inmanencia formal de estas novedades editoriales la cifra metonímica de encrucijadas culturales más abarcadoras. Desarrolla, a partir del comentario bibliográfico, una poética y política de las diferencias que hace de la crítica un último reducto discursivo, un espacio específicamente textual donde resulte posible sostener una apuesta por la confrontación irreductible a todo imperativo consensual.

\section{FUEGO AMIGO}

La opción formal de Cardín por la polémica halla su instancia paradigmática de realización en el intercambio de cartas abiertas que inaugura Diwan 7, cuando pliega las armas de la crítica sobre sí mismas y da lugar a una discusión, interna y pública a la vez, entre los mismos directores de la revista. Antes expuesta en sus invectivas a Savater, la vocación confrontacional de Cardín ahora se expresa en el gesto auto-reflexivo que Peller reconoce como rasgo distintivo de la "pasión teórica" (2016: 323), en el exceso auto-crítico de un intelectual teórico que se afirma como tal, paradójicamente, a través de la interrogación y puesta en crisis de su propia instancia enunciativa. En estas cartas abiertas, Cardín cuestiona auto-conscientemente qué figura de sujeto intelectual debe postular la revista al intervenir en los debates que signan su contexto: saca a la luz de este modo, hacia el interior de la propia Diwan, la falacia de un llamamiento generalizado al consenso que somete e invisibiliza oposiciones irreductibles en el campo cultural posfranquista.

Con título "Para guardar las formas", Jiménez Losantos inicia el intercambio con una carta donde propone ceder a Cardín el puesto de Director de la publicación, "nominal, ya que la dirección real ha sido siempre colegiada" (1979: 7), a fin de evitar equívocos entre la línea intelectual seguida por Diwan y la militancia y candidatura partidarias que él mismo, por entonces, desarrolla en el Partido Socialista de Aragón en Cataluña. Para Jiménez Losantos, tal "traspaso de mando" sería mera cuestión de formas, ya que la orientación programática de su candidatura no sería ajena a la "línea política de fondo" de Diwan. Declara sin embargo su voluntad de continuar con el cariz independiente, sin "mediatización partidista alguna", de la "labor cultural" emprendida hasta el momento por la revista: "no cabe duda de que la actividad política puede llevar directa o indirectamente a ciertos compromisos que afecten, siquiera parcialmente, por acción o por omisión, a la total independencia crítica que es la razón de ser de Diwan” (1979: 7).

Al "guardar las formas" de Jiménez Losantos, a los matices retóricos que este introduce al caracterizar su práctica tanto crítica como política, Cardín replica redoblando la apuesta. "También cuenta la sustancia", titula su carta de respuesta, donde hace de las formas discursivas y retóricas, justamente, la sustancia de una toma de partido intelectual de largo alcance:

Se trata, como tú dices, de una pura formalidad, pero las formalidades y los procedimientos - este mismo intercambio de cartas y su publicación- no solo están cargadas de sentido por el hecho mismo de existir, sino que además establecen posiciones [...] Nada mejor que esta renuncia para significar mediante una formalidad el sentido 
básico de Diwan, para establecer mediante un acto simbólico lo que en adelante debe constituir la línea básica de actuación de esta revista, libre hasta donde pueda estarlo [...] de las confusiones que la actual situación cultural impone. (1979: 10)

Las "formalidades y procedimientos" de una "revista libre" son para Cardín ocasión de recurrir a la noción de autonomía, con la que traza simetrías entre la situación marginal de Diwan y su propia polémica con Jiménez Losantos: "La situación de cerco cultural en que esta revista y cada uno de sus miembros se mantienen [...] puede conducir, como ha ocurrido en tu caso, a buscar una solución en la práctica política" (1979: 10). Cardín asume la discrepancia individualizada como enseña y motor de la práctica crítica, la cual demandaría para su despliegue la consolidación de la autonomía relativa del campo cultural. Frente al proyecto electoralista de Jiménez Losantos, Cardín sostiene que solo posicionándose a distancia de todo imperativo, sea político-partidario o editorial-comercial, el intelectual podría asumir la palabra bajo dictados realmente propios y así llevar adelante la discusión abierta que la transición urge por instaurar:

Y por más que quienes practican dicha organicidad se empeñen en convencernos de que lo difícil es la síntesis (lo que ellos llaman "síntesis", es decir, la confusión de niveles, de personas, de organismos, la connivencia, el conchabamiento político cultural, en suma), difícilmente conseguirán cambiar lo que está inscrito en el término que resume el motor de la cultura occidental desde sus orígenes: la crítica (krino, cerno: separar, tamizar) [...] Sobre esta base hemos actuado siempre, errando en lo menos, por acertar en el método, que no es otro que la discusión constante. (1979:10)

Cardín cataloga de este modo de "conchabamiento político cultural" el intento de Jiménez Losantos por aunar trabajo intelectual e institucionalización partidaria. Frente a la "confusión de niveles" que tal empresa reportaría, reafirma su apuesta por delinear un campo propio de acción en el gesto y la escritura de la crítica, cuyo método asocia al sostenimiento de una "discusión constante" y a un ejercicio de la polémica abierta, pública y, sobre todo, sostenida en primera persona del singular. Sin embargo, la apelación de Cardín a la autonomía no resulta ingenua: mientras se sabe material y fácticamente improbable, tal como podría desplegarse a partir del concepto de posautonomía propuesto por Josefina Ludmer ${ }^{5}$, la autonomía actúa en su escritura como recurso y categoría de "imaginación crítica". En términos de Marcelo Topuzian:

que la autonomía no se haya [...] realizado de manera total o absoluta o que no haya estado ligada a un conjunto de criterios prefijado para reconocerla como tal, no quiere decir que ella no haya conformado una fuente productiva de imaginación crítica. (2013: 322)

No se trata entonces de evaluar y constatar si tal o cual estado del campo cultural posfranquista satisface fehacientemente los requisitos de la condición de autonomía, sino de dar cuenta de su operatividad en tanto concepto, o incluso anhelo, cuando Cardín delimita con él un espacio específicamente discursivo desde donde lanzar un proyecto de crítica radical:

\footnotetext{
5 Para Ludmer, el fin del siglo XX atestiguaría el declive de la literatura concebida como esfera o campo autónomo de acción: el avance de los medios audiovisuales y la industria del libro erosionaría "el poder crítico, emancipador y hasta subversivo que le asignó la autonomía a la literatura", para en cambio enfrentarla a criterios de valor extraliterarios: "Todo depende de cómo se lea la literatura hoy [...] O se ve el cambio en el estatuto de la literatura en el interior de la industria de la lengua, y entonces aparecen otros modos de leer. O no se lo ve o se lo niega, y entonces seguiría habiendo literatura y no literatura, o buena y mala literatura" (2010: 154-155).
} 
Un nuevo estadio de Diwan debe abrirse ahora [...] en el que cada miembro de la redacción mantenga su palabra propia, sin ser confundido con la de cualquier otro, en el que Diwan sea de verdad lo que desde el principio [...] ha pretendido ser: un fermento crítico, un espacio de debate cultural sin límites de género ni forma, un ejemplo de independencia de criterio que no teme riesgos. Y esto [...] hemos de hacer lo posible por practicarlo nosotros mismos y con nosotros mismos. (1979: 11)

Su demanda de autonomía del campo cultural revela ser no solo un hipotético escenario ideal donde el ejercicio crítico podría concretar plenamente sus lineamientos, sino además un marco textual que habilita el despliegue de la polémica. Solo habría verdadera crítica cuando el intelectual se muestre capaz, en su figuración textual como sujeto crítico y a la par que desmonta aquella de su eventual oponente, de dar cuenta de su propia instancia enunciativa. Tal como demuestra el "practicarlo con nosotros mismos" que clausura su carta, es el preciso gesto autoreflexivo de la "pasión teórica" el medio discursivo con que el intelectual justifica y dispone las condiciones de posibilidad de su propia intervención. Cardín encuentra en el movimiento electoralista de Jiménez Losantos la oportunidad de plegar los procedimientos de la crítica y la polémica sobre sí mismos: antes dirigidos hacia sus antagonistas arquetípicos como Savater, Aranguren o Goytisolo, ahora interrogan, ponen en crisis y reconfiguran, desde el espacio de la carta y en nombre propio, la figura del intelectual promovida por su propia revista Diwan.

El intercambio de cartas abiertas vuelve a repetirse como método y condición constitutiva de la revista en Diwan 10, ahora iniciado por Cardín en ocasión de hacer públicas las razones de su renuncia y salida de la publicación. Cardín reafirma la carta abierta como espacio discursivo de contienda inter pares, donde el recurso formal a la polémica se traduce en dispositivo de "ultimar el finiquito intelectual de mi relación con Diwan". Reconstruye los dimes y diretes de la publicación de su propia carta, evocando un altercado con el ahora exclusivo director Jiménez Losantos sobre los plazos de entrega y cierre de este número. Cardín recuenta una conversación telefónica en la que Jiménez Losantos habría sugerido que, de "contener algún insulto personal", su carta no sería incluida por "emporcarlo todo con mis chismes". Denuncia Cardín la flagrante contradicción entre tal actitud y la línea de la revista durante dos años, a cuyo ejemplo señala la ya citada "Psicosis" de Masotta y sus ataques a Savater: "mantuve en la conversación telefónica que el insulto califica más a quien lo profiere que a quien va dirigido, pero, por lo que a este último se refiere, acierta siempre [...] porque es siempre un crimen de lesa majestad" (1980: 129).

Para Cardín, su presencia en Diwan sería tanto personal como textualmente incompatible con todo afán de lograr reconocimiento institucional para la revista. Recuerda su colocación lateral en el campo cultural español y traza desde allí un paralelo entre los desplazamientos que, tanto en condiciones como en formas de enunciación, habría emprendido Jiménez Losantos:

Cuando Federico Jiménez intentó imponerme el punto de giro de Diwan lo hizo con afanes de institucionalización. Lo dijo así claramente, no es invento mío: Diwan necesitaba institucionalizarse para poder ser reconocida [...] Tenía que morir a su vida anterior para renacer a una nueva: sin otrosí, sin reseñas virulentas, sin mandobles a pie de página, obras, todos estos aspectos molestos, de quien estas páginas escribe. (1980: 131)

Tras su fallida experiencia electoral con PSA y como él mismo expresa en Lo que queda de España, Jiménez Losantos opta por "no ir más allá de donde se puede”, es decir, por un repliegue programático al interior de Diwan: "no era aceptable que en el número 8/9 Alberto hubiera 
hecho todas las críticas y casi todas las reseñas, dedicando cada una de ellas a sus enemigos favoritos" (1995: 111). Cardín denuncia este viraje tanto en la incorporación de nuevas firmas a la revista, entre las que se cuentan antiguos detractores como Juan Manuel Bonet, como en el "descarte" de su sección "Otrosí" y la forma textual allí desplegada:

¡Mientras Diwan languidecía en el aislamiento hasta los mismos que ahora forman su consejo de redacción la atacaban! [...] De no ser por mi obsesividad y mi sentido paranoico de la lucha cultural, Diwan no hubiera podido tener continuidad. (1980:130)

Al prescindir de "reseñas virulentas" y "mandobles a pie de página", Diwan no reflejaría más que la "ambición social" y "deseo de reconocimiento" de Jiménez Losantos, meta inalcanzable desde el posicionamiento intelectual de Cardín, quien hace de forma y sustancia dos caras de una misma vocación de margen y contienda:

Nada como el odio para conocer, [...] nada como el margen para descubrir los efectos del centro, aunque el marginado ponga a contribución su interés resentido [...] En el exceso acertará siempre: tal vez no en el método o en los matices, pero sí en el señalamiento de los puntos cruciales. (1980: 130)

En su carta de respuesta, Jiménez Losantos comienza por delimitar las vertientes distintivas que cada uno representa al interior de Diwan. Prioriza su continua preocupación por el "tema de España” y relega a ocurrencia menor la dedicación de Cardín a la polémica desde "Otrosín":

Parecía excesivo que apareciese continuamente la misma firma debajo de todas las notitas bibliográficas de actualidad, pero el empeñando en opinar peyorativamente sobre cualquier cosa que apareciese en El País o cualquier revista, no era precisamente yo. (1980: 133)

Jiménez Losantos precisa el punto de quiebre detrás de la crisis y ruptura con su antiguo aliado, una discusión vinculada a la inclusión de una implacable reseña de Cardín a La prensa en la calle (1980) de Juan Luis Cebrián. Para Jiménez Losantos, Diwan no podía permitirse mantener una "línea de venganzas personales" y objeta el texto de Cardín por "arbitrario" y "preconcebidamente insultante", manifestando su intención de añadir a continuación una reseña propia "para que se entendiera que la redacción no compartía los términos de la suya" (1995: 111). El "no ir más allá de donde se puede" de Jiménez Losantos se traduce en negativa a atacar a un estimable aliado en el campo cultural como Cebrián, director de El País desde su fundación: "Diwan no podía estar, por principio, atacando a cualquiera por ser de El País, [...] donde Ullán y Pradera nos habían ayudado tanto y donde se había defendido a capa y espada Lo que queda de España" (1995: 112).

En su desestimación de las "notitas bibliográficas de actualidad", Jiménez Losantos demarca su propio programa intelectual de aquella apelación de Cardín a la polémica como enseña del ejercicio crítico. La discrepancia entre ambos refiere tanto a estrategias contrapuestas de afinidades o contrastes con actores del campo cultural como a la forma textual desde donde impulsarlas. Mientras Cardín hace no solo de lo personal, sino hasta del resentimiento y del insulto una política de la crítica, Jiménez Losantos aboga por una crítica alejada de las "gacetillas maniáticas", capaz de perfilar y mantener distancias entre las esferas personal y política: 
¿Tú crees que se puede sostener cualquier política cultural partiendo de que periodista, poeta, novelista, filósofo o político [...] es vituperable por principio, desde no importa qué punto de vista ni de qué maneras? Una cosa es atacar a cualquiera con alguna razón y otra atacar a alguien que nos molesta con cualquier razón. (1980: 134)

Tal como expresa Jiménez Losantos, la salida de Cardín de Diwan obedece a su incorregible afán por "vituperarlo todo", ademán que resulta contraproducente al proyecto de establecer a la revista como instancia de referencia. Atacar a cualquiera con cualquier razón, justamente, el punto de partida desde el que Cardín concibe el ejercicio crítico: hacer de la polémica tanto una voluntad de intervención como una forma discursiva específica, con la cual delatar e interrogar las condiciones del decir subyacentes a lo dicho. En Cardín, la controversia ad honorem opera como momento de inaugural y radical negatividad, pero también como umbral "para otra cosa". Como dice Jinkis sobre las intervenciones críticas de Masotta: "más allá del interlocutor circunstancial, construye un discurso disidente con el contexto que apunta a socavar la autoridad de lo instituido" (2019: 70). Un posición heterodoxa, de ruptura, que elige un oponente, devela y denuncia sus condiciones de enunciación, para así poner en jaque una estructura "más grande", el campo cultural posfranquista donde la misma distribución de roles e instancias enunciativas tiene lugar. Se contradicen per se los argumentos del otro, pero con ellos se sacude algo más. Más allá de los planteos ideológicos explícitos de cada figura intelectual, Cardín apunta a las condiciones de posibilidad que habilitan, en primera instancia, la presencia y visibilidad de sus voces en un escenario signado por el reordenamiento de referencias de opinión.

\section{ESTOICISMO LACANIANO}

En una transición democrática caracterizada por la dual e interdependiente normalización de las esferas política y cultural, Cardín combate el reacomodamiento de figuras intelectuales, desde Aranguren a Savater, desde Cebrián a Jiménez Losantos, hoy catalogadas más o menos despectivamente como "intelectuales mediáticos", "establecidos" o "desfachatados", cuyas apariciones públicas indefectiblemente contribuirían a la consolidación del marco consensual dictado por las elites partidarias. Frente a ellos, Cardín caracteriza su intransigente postura intelectual como la "organicidad diferenciada" de un "estoicismo lacaniano" (1980: 10). Como afirma Masotta en su seminario en Barcelona, el "corte entre psicoanálisis y política" se juega en "analizar los emblemas como significantes y descubrir tras ellos una trama de otro tipo" (2015: 209). Replica así, de cara al acontecer de "lo político", el método crítico con que en su lectura sintomática forzaba al texto a hablar "sobre aquello que casualmente decide no hablar" (1990: 64). Mientras la política procedería por identificación (con un proyecto o valor superior), el psicoanálisis des-idealizaría al sujeto devolviéndolo a la vacuidad fundacional y primordial de su deseo: "el sujeto puede apropiarse de valores, desde el punto de vista de la derecha o de la izquierda, positivos o negativos, pero los utiliza por el motivo narcisista" (2015: 209). La política de la crítica que Cardín define como "estoicismo lacaniano" reflecta entonces el rigor autoreflexivo que Masotta adjudica al rol del "intelectual teórico". Se trata, para Cardín, de dar cuenta de los impasses paradójicos de un sujeto crítico situado en contexto, sea al apuntar los lapsus contradictorios entre enunciación y enunciado, como en sus ataques a Savater, sea al personificar él mismo la paradoja de una postura intelectual sin institucionalización posible, cuya "admisión" en el campo cultural posfranquista resultaría insoportable para las propias reglas del juego. 
Al momento de su muerte, planificaba Cardín una compilación de sus trabajos de crítica literaria bajo el título de El vicio de criticar. Vicio caracterizado por el propio Cardín, en carta a Manuel Borrás, editor de Pre-Textos, como el imperativo de "ser con los demás tan implacable como pretendo ser conmigo mismo". El recurso a la teoría y la apelación a la polémica, en definitiva, confluyen para Cardín en la especificidad discursiva de una crítica que se define como tal únicamente mediante la asunción radical del conflicto y la diferencia irreductibles. Cardín apuesta por la confrontación abierta y en primera persona del singular, allí donde una transición democrática dirigida "desde arriba" impondría el llamamiento al consenso y al "bien común" como mandato. La irrupción de un "Lacan en porteño" en España, el vínculo intelectual entablado con Masotta, impregnan de "pasión teórica" las intervenciones críticas de un Cardín obstinado en interrogar qué sujeto intelectual adviene al renovado escenario posfranquista. Para Cardín, el ascendente influjo de medios como El País sobre la opinión pública española constata en clave cultural el abanico de "lo posible" dispuesto por los representantes del marco político consensual: en su rol de "referencia dominante", la industria cultural determina inclusiones y exclusiones, consagra o condena al olvido tanto a personalidades como a los géneros textuales donde estas se manifiestan. Si Cardín se propone boicotear la autoridad unánime y aparentemente incuestionable de grandes nombres intelectuales, lo hace desde la propia forma discursiva en que estos cimentan su celebridad. Desde el comentario bibliográfico en las páginas de su "Otrosí", desde el intercambio de cartas abiertas al interior de su propia revista Diwan, Cardín hace de forma y sustancia dos facetas indisociables de una misma toma de partido, de una voluntad de contienda que cifra en la inmanencia del estilo un posicionamiento intelectual "a la contra".

Desmesura e incomodidad, diatriba y polémica, desenmascaramiento ideológico y autoexamen, son entonces rasgos distintivos de una apuesta programática por la crítica en tanto ámbito propio y específico de intervención. Ante el estrechamiento de canales de difusión, ante el progresivo "descarte" de sus embestidas incordiosas tanto en publicaciones propias como ajenas, Cardín hace de la ausencia de institución una institución eficaz: en la elección de la forma establece el espacio de combate, en la especificidad textual de sus intervenciones configura el marco de autonomía necesario para el despliegue de una propuesta crítica intransigente y radical. Implacable consigo mismo y con los demás, Cardín ofrece en su propia vocación marginal una clave interpretativa y un medio de confrontación al reordenamiento intelectual de su tiempo. Su figura y sus desafíos polémicos corporizan el punto excesivo de la discusión constante, forzando a sus interlocutores a dar cuenta de sus condiciones de enunciación y resultando por ello insoportable a la normalización "oficial" y "pacífica" del escenario posfranquista. Cardín dispara una demanda que se sabe inalcanzable y allí mismo encuentra su potencia de interrogación, demanda de honestidad brutal por parte de quienes detentan el poder de la palabra, que expone el consabido "cambiar todo para que nada cambie" con que las líneas hegemónicas de la transición democrática han pretendido obturar vías alternativas y disidentes de política y cultura en España. 


\section{BIBLIOGRAFÍA}

AliagA, Juan Vicente y CORTÉs, José Miguel (eds.) (1993). De amor y rabia: acerca del arte y el sida. Valencia: Universidad Politécnica de Valencia.

Asensi PÉReZ, Manuel (2006). Los años salvajes de la teoría. Ph. Sollers, Tel Quel, y la génesis del pensamiento post-estructural francés. Valencia: Tirant lo Blanch.

Bonet, Juan Manuel. "Presentación de las revistas ‘Diwan' y 'Trama”. El País (11/05/1978).

BuCKLEY, Ramón (1996). La doble transición: politica y literatura en la España de los años setenta. Madrid: Siglo XXI.

CARDín, Alberto (1981). Como si nada. Valencia: Pre-textos.

CARDín, Alberto (1993). Un cierto psicoanálisis. Madrid: Libertarias/Prodhufi.

CARDín, Alberto (2016). Mi más hermoso texto. Barcelona: Ultramarinos.

Castro, Ernesto (2016). "Prólogo: superficialidades". Cardín, Alberto. Mi más hermoso texto. Barcelona: Ultramarinos.

CATELLI, Nora. "Indiscernible: literatura y psicoanálisis en una orilla atlántica". El taco en la brea 6 (2017): 9-22.

CAYUELA SÁNCHEZ, Salvador (2010). La biopolítica en la España franquista. Tesis doctoral. Murcia: Universidad de Murcia.

CRESPI, Maximiliano (2011). Conspiración de las formas. La Plata: UNIPE Editorial Universitaria.

De Miguel, Armando (1980). Los intelectuales bonitos. Barcelona: Planeta.

Delgado Ruiz, Manuel (1997). "Pensar en contra". Cardín, Alberto. Contra el catolicismo. Barcelona: Muchnik Editores.

Diwan 1-12 (1978-1982).

Druet, Anne-Cécile. "Psicoanálisis y transición democrática en España". História, Ciências, Saúde 24 (2017): 63-78.

El Viejo Topo 26, 29 (1978-1979).

GARCÍA, Germán (2005). El psicoanálisis y los debates culturales: ejemplos argentinos. Buenos Aires: Paidós.

GARCÍA, Germán (2018). "Política y clínica: a propósito de la hiperactividad”. Mazza, César. Palabras de ocasión: entrevistas a Germán García. Córdoba: Los ríos.

GIORDANO, Alberto (1999). Razones de la crítica: sobre literatura, ética y politica. Buenos Aires: Colihue.

Giordano, Alberto (2005). Modos del ensayo: de Borges a Piglia. Rosario: Beatriz Viterbo Editora.

GraCIA, Jordi (2019). Javier Pradera o el poder de la irquierda. Barcelona: Anagrama (Edición Kindle). IDEZ, Ariel Darío (2010). Literal: la vanguardia intrigante. Buenos Aires: Prometeo. 
ImBERT, Gérard y VidAl Beneyto, José (eds.) (1986). El País o la referencia dominante. Barcelona: Mitre.

JimÉnez Losantos, Federico (1995). Lo que queda de España. Madrid: Temas de hoy.

JINKIS, Jorge. "El psicoanálisis, punto de llegada”. Tiempo Argentino (25/11/1984).

JINKIS, Jorge. “Una pasión intelectual”. Conjetural 70 (2019): 63-80.

LABRADOR MÉNDEZ, Germán (2017). Culpables por la literatura: imaginación política y contracultura en la transición española (1968-1986). Madrid: Akal (Edición Kindle).

LACAN, Jacques (2013). Otros Escritos. Buenos Aires: Paidós.

LACRUZ NAVAS, Javier (2002). El grupo de Trama. Zaragoza: Mira Editores.

LóPez, Silvia; Talens, Jenaro y Villanueva, Darío (eds.) (1994). Critical Practices in Post-Franco Spain. Minneapolis: University of Minnesota Press.

Ludmer, Josefina (2010). Aqui América Latina: una especulación. Buenos Aires: Eterna Cadencia.

MARTíneZ, Guillem (ed.) (2012). CT o la cultura de la transición. Barcelona: Debolsillo (Edición Kindle).

MASOTTA, Oscar (1990). El modelo pulsional. Buenos Aires: Argonauta.

MasotTA, Oscar (2010). Conciencia y estructura. Buenos Aires: Eterna Cadencia.

MAsotTA, Oscar (2015). Lecturas de psicoanálisis: Freud, Lacan. Buenos Aires: Paidós.

MENDOZA, Juan José (2011). “El proyecto Literal'. Literal: edición facsimilar. Buenos Aires: Biblioteca Nacional.

MirA, Alberto (1999). Para entendernos: diccionario de cultura homosexual, gay y lésbica. Barcelona: Libros de la Tempestad.

Mira, Alberto (2004). De Sodoma a Chueca: una historia cultural de la homosexualidad en España en el siglo XX. Barcelona: Egales.

MORÁn, Gregorio (2014). El cura y los mandarines: historia no oficial del Bosque de los Letrados: cultura y política en España 1962-1996. Madrid: Akal (Edición Kindle).

MORÁN, Gregorio (2015). El precio de la transición. Madrid: Akal (Edición Kindle).

NAZARIO (2016). La vida cotidiana del dibujante underground. Barcelona: Anagrama.

PeCOURT, Juan (2008). Los intelectuales y la transición: un estudio del campo de las revistas políticas en España. Madrid: Centro de Investigaciones Sociológicas.

PeCOURT, Juan (2016). "Del papel a la pantalla. El recorrido mediático de la inteligencia antifranquista". Bulletin d'Histoire Contemporaine de l'Espagne 50 (2016): 111-125.

Peller, Diego (2016). Pasiones teóricas: crítica y literatura en los setenta. Buenos Aires: Santiago Arcos.

Plata Parga, Gabriel (2010). De la revolución a la sociedad de consumo. Madrid: Universidad Nacional de Educación a Distancia. 
Pliegos de producción artística 1-5 (1974-1974).

PONS, Margalida. "Aproximació a la narrativa experimental postfranquista". Catalan Review 1-2 (2005): 173-196.

QUAGGIO, Giulia (2014). La cultura en transición: reconciliación y politica cultural en España, 1976-1986. Madrid: Alianza (Edición Kindle).

Revista de Literatura 1-6/7 (1974-1977).

RiBAS, Pepe (2017). Los '70 a destajo: Ajoblanco y libertad. Barcelona: Planeta.

SÁNCHEZ-CuENCA, Ignacio (2016). La desfachatez intelectual: escritores e intelectuales ante la política. Madrid: Los libros de la catarata (Edición Kindle).

Savater, Fernando (1978). Panfleto contra el Todo. Barcelona: Dopesa.

SAVATER, Fernando (1994). La infancia recuperada. Madrid: Taurus.

SMith, Paul Julian (2000). The moderns: time, space and subjectivity in contemporary Spanish culture. New York: Oxford University Press.

TOPUZIAN, Marcelo. "El fin de la literatura. Un ejercicio de teoría literaria comparada". Castilla: estudios de Literatura. 4 (2013): 298-349.

Trama: revista de pintura 0-1/2 (1976-1977).

VILARÓs, Teresa (2018). El mono del desencanto: una crítica cultural de la transición española (1973-1993). Madrid: Siglo XXI (Edición Kindle).

VILASECA, David (2010). Queer events: post-deconstructive subjectivities in Spanish writing and film, 1960s to 1990s. Liverpool: Liverpool University Press.

WOLFF, Jorge (2009). Telquelismos latinoamericanos. Buenos Aires: Grumo. 